\title{
Retraction note to: Brassica RNA binding protein ERD4 is involved in conferring salt, drought tolerance and enhancing plant growth in Arabidopsis
}

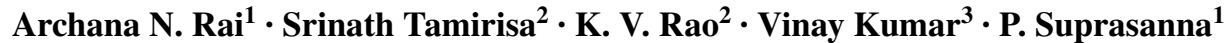

Published online: 18 January 2017

(C) Springer Science+Business Media Dordrecht 2017

\section{Retraction note to: Plant Mol Biol (2016) 90: 375-387 DOI 10.1007/s11103-015-0423-x}

This article has been retracted by the authors due to the fact that panels in Fig. 3c are duplicated for different transgenic lines. All authors have agreed to the retraction of this paper and deeply regret the duplication. The authors maintain that the duplication does not affect the interpretation or conclusions of their study. They will seek to publish the results in a new manuscript with a corrected version of the figure to corroborate the findings of this work. The authors deeply regret the inconvenience caused by the retraction.

The online version of the original article can be found under doi:10.1007/s11103-015-0423-x. This article should be considered as retracted.

P. Suprasanna

penna888@yahoo.com; prasanna@barc.gov.in

1 Plant Stress Physiology and Biotechnology Section, Nuclear Agriculture and Biotechnology Division, Bhabha Atomic Research Centre, Mumbai 400085, India

2 Centre for Plant Molecular Biology, Osmania University, Hyderabad 500007, India

3 Solid State Physics Division, Bhabha Atomic Research Centre, Mumbai 400085, India 